\title{
MODULAR UNCEMENTED PROSTHETIC RECONSTRUCTION AFTER RESECTION OF TUMOURS OF THE DISTAL FEMUR
}

\author{
R. CAPANNA, H. G. MORRIS, D. CAMPANACCI, M. DEL BEN, M. CAMPANACCI
}

From the University of Bologna, Italy

We report the use of the uncemented Kotz modular femur and tibia reconstruction system after 95 distal femoral resections performed from 1983 to 1989 . The average follow-up was 51 months; 62 patients had at least 36 months' follow-up and 36 at least 60 months.

Complications required reoperation in $55 \%$. The postoperative infection rate was $5 \%$ for primary cases, $6 \%$ for revision cases, and $43 \%$ for revision of previously infected cases. The polyethylene bushes failed in $42 \%$ of cases at an average of 64 months postoperatively. Stem breakage occurred in $6 \%$ and was associated with the use of narrow stems and extensive quadriceps excision.

The radiological results were excellent or good in most cases and were related to the initial screw fixation, but not to age, chemotherapy, length of resection or size of stem. The clinical results were excellent or good in $75 \%$, failure usually being associated with a complication, especially infection.

J Bone Joint Surg [Br] 1994; 76-B:178-86.

Received 30 March 1993; Accepted after revision 27 July 1993

Limb-salvage surgery is an accepted method of treatment for selected sarcomas of the extremities. Various methods of segmental reconstruction have been described. These include arthrodesis with autograft or allograft; rotationplasty; bone-transport techniques, such as that of Ilizarov; resection and reinsertion of bone after autoclaving or irradiation; and arthroplasty using allografts, allograft composites and endoprostheses. The survival rates of patients have improved with better chemotherapy, radiotherapy, and techniques of surgical resection. For this

R. Capanna, MD, Consultant

H. G. Morris, FRACS, Fellow in Musculoskeletal Oncology

D. Campanacci, MD, Resident

M. Del Ben, MD, Resident

M. Campanacci, MD, Professor

First Orthopaedic Clinic, University of Bologna, Istituto Ortopedico Rizzoli, Via Pupilli 1, 40136 Bologna, Italy.

Correspondence should be sent to Dr R. Capanna.

C1994 British Editorial Society of Bone and Joint Surgery 0301-620X/94/2686\$2.00 reason, the long-term behaviour and functional ratings of various types of reconstruction are important, especially as many patients are young.

One method of endoprosthetic reconstruction, used at the Rizzoli Orthopaedic Institute since 1982, is the Kotz modular femur and tibia resection system (KMFTR; Fig 1; Kotz, Ritschl and Trachtenbrodt 1986). We have reviewed our experience with 95 distal femoral reconstructions and studied several aspects of the results. We attempted to correlate the long-term radiological changes with the age of the patient, chemotherapy, length of resection, diaphyseal stem diameter and the number of screws inserted across the stem of the prosthesis. The clinical results were related to the radiological findings, and the complications associated with the use of the prosthesis were recorded.

\section{PATIENTS AND METHODS}

Between 1983 and 1989, we performed 95 distal femoral resections (Table I), all reconstructed with the KMFTR system (Fig. 1). The average age of the patients was 23 years (11 to 69); there were 55 males and 40 females. The average follow-up was 51 months ( 2 to 102 ); 62 patients were followed up for at least three years and 36 for at least five years (Fig. 2). Radiological results were assessed only in the 62 patients with a minimum three-year followup. One patient died early from pulmonary embolism and one had an early amputation due to a vascular complication. These patients are discussed only in relation to complications.

The standard preoperative workup included history and clinical examination, routine laboratory tests and anaesthetic assessment, plain radiography, CT scans of the leg and chest, a ${ }^{99 \mathrm{~m}} \mathrm{Tc}$ bone scan and, in most cases, MRI of the leg. Patients who were having intra-arterial chemotherapy had an angiogram. Prophylactic antibiotics were given before operation.

Operation was by an anterolateral or anteromedial approach, depending on the biopsy site. Early in the series, several patients had detachment of the tibial tuberosity and reattachment with a screw, but we no longer use this method. The neurovascular bundle was identified and dissected free. The tumour was then 


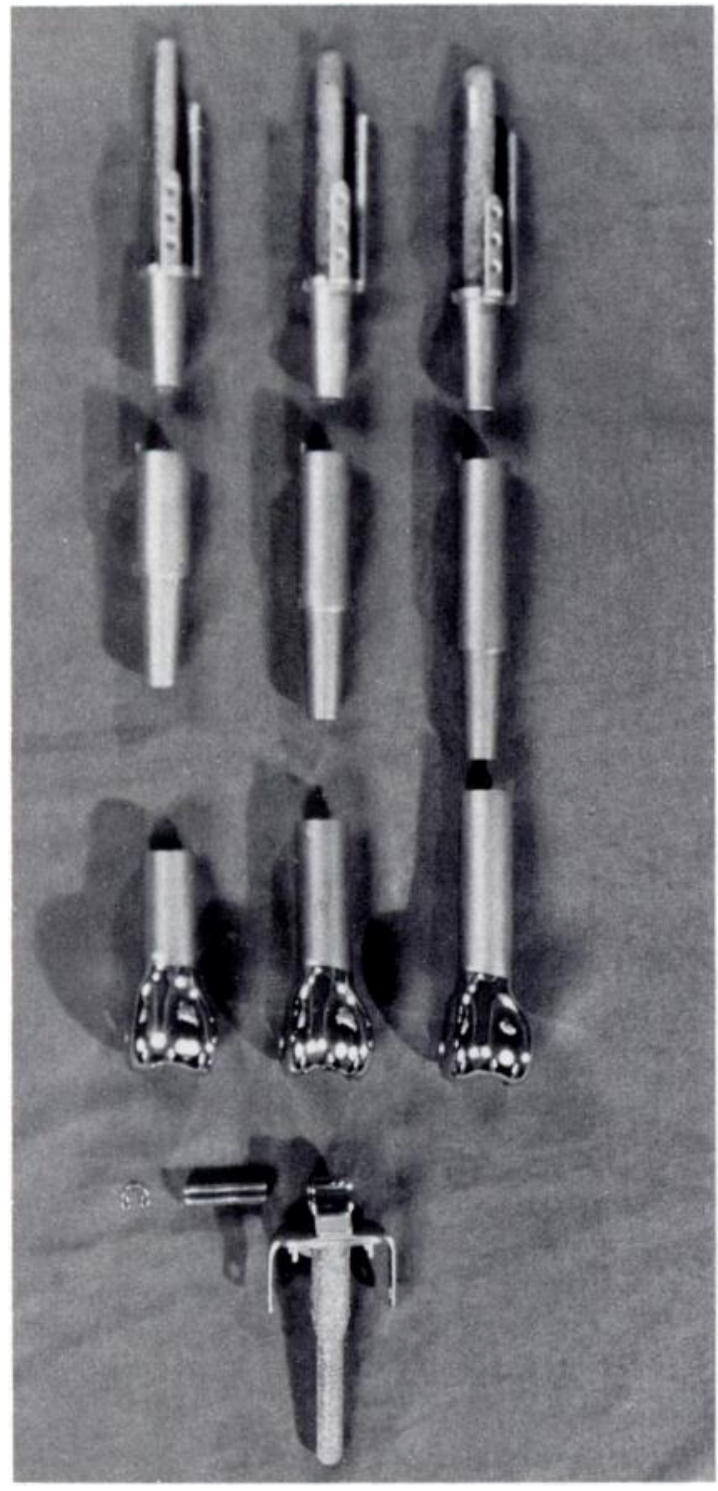

Fig. 1

The Kotz modular femur and tibia resection system (KMFTR) is modular and allows resections of any length greater than $12 \mathrm{~cm}$.

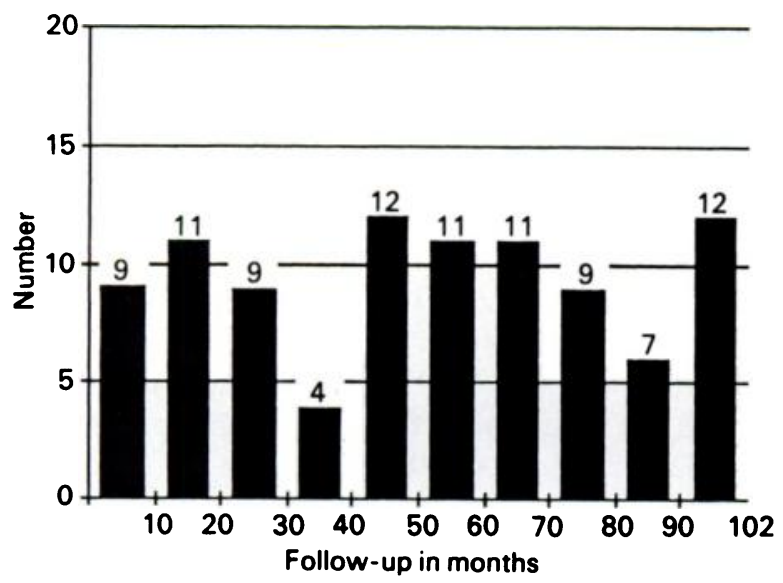

Fig. 2

Duration of follow-up in 95 patients. resected with a surrounding cuff of normal tissue, attempting to achieve a wide surgical margin. Reconstruction was done with the KMFTR system. The patella was not routinely resurfaced, but in the early years of this study 12 patellae were replaced.

Excision of the quadriceps included vastus intermedius only in 7 cases, vastus intermedius and vastus lateralis in 21 , vastus intermedius and vastus medialis in 17 , all three vasti in 27 , and all three vasti plus rectus femoris in 10. The other 13 cases were conversions from previous knee arthrodeses. The surgical margins, defined both grossly and histologically, were radical in none, wide in 80 , wide but contaminated in 6 , marginal in 8 and intralesional in 1.

Of the 95 cases, 18 were revision procedures: nine for fracture of a $\mathrm{K}$ nail used with cement, five for an infected $\mathrm{K}$ nail with cement, one for infection after plating and cement, two after curettage and cement or bone graft, and one after the fracture of an infected allograft which had been inserted elsewhere.

Technique of operation. The vitallium diaphyseal anchorage of the system is an intramedullary stem with two lateral flanges at right angles to each other, each with three holes to allow the passage of a total of six screws through the stem and cortex (see Fig. 1). The longer plate is placed laterally. The stem has a fully madreporic surface and is straight, with a choice of 10,13 and $16 \mathrm{~mm}$ diameters. At operation the medullary canal is reamed to accept the nearest sized stem as a press fit. This is then stabilised with cross screws, using all six holes for 'complete fixation', or three or less for 'incomplete' fixation. This diaphyseal component is connected to the femoral condylar component by a morse taper, allowing for a minimum resection length of $12 \mathrm{~cm}$, increasing in increments of $2 \mathrm{~cm}$.

The vitallium tibial metaphyseal replacement component has a stem and two lateral flanges. In our series we pressed only the medial flange against the cortex and used no screws. Both the stem and the base plate have full madreporic coatings. At operation, the proximal tibia is cut just below the articular cartilage, and the metaphysis and diaphysis are reamed to provide a press fit.

The prosthetic joint is a flexion-extension hinge with its centre of rotation offset posteriorly, the metal components being linked by two polyethylene bushes. Trial reduction is used to test range of motion, leg length, and the stability and tension of the soft tissues. The prosthesis is covered with remaining local musculature and fascia before the wound is closed over large-bore suction drains.

At day 5 or 6 after operation, most of the patients were treated by a continuous passive motion (CPM) machine for seven days until they had regained $60^{\circ}$ of flexion, but the early patients who had tibial tuberosity detachment and screw reattachment were placed in a plaster cast for one month. Intravenous antibiotics were continued for three days, when the drains were removed if drainage was minimal. Active movements began when 
Table I. Histological diagnosis and stage (Enneking 1987) in 95 cases

\begin{tabular}{|c|c|c|c|c|c|c|c|c|}
\hline \multirow[b]{2}{*}{ Diagnosis } & \multirow[b]{2}{*}{ Number } & \multirow[b]{2}{*}{ Subtype } & \multirow[b]{2}{*}{ Number } & \multicolumn{5}{|c|}{ Stage } \\
\hline & & & & Ia & Ib & IIa & IIb & III \\
\hline Osteosarcoma & 63 & $\begin{array}{l}\text { Osteoblastic } \\
\text { Chondroblastic } \\
\text { Fibroblastic } \\
\text { Telangiectatic } \\
\text { Parosteal }\end{array}$ & $\begin{array}{r}54 \\
2 \\
2 \\
2 \\
3\end{array}$ & $\begin{array}{l}0 \\
0 \\
0 \\
0 \\
1\end{array}$ & $\begin{array}{l}0 \\
0 \\
0 \\
0 \\
2\end{array}$ & $\begin{array}{l}2 \\
0 \\
0 \\
0 \\
0\end{array}$ & $\begin{array}{r}48 \\
2 \\
2 \\
2 \\
0\end{array}$ & $\begin{array}{l}4 \\
0 \\
0 \\
0 \\
0\end{array}$ \\
\hline Ewing's sarcoma & 2 & & & 0 & 0 & 0 & 2 & 0 \\
\hline $\mathrm{MFH}^{*}$ & 7 & & & 0 & 1 & 0 & 5 & 1 \\
\hline Chondrosarcoma & 6 & $\begin{array}{l}\text { Chondrosarcoma } \\
\text { Dedifferentiated }\end{array}$ & $\begin{array}{l}4 \\
2\end{array}$ & $\begin{array}{l}0 \\
0\end{array}$ & $\begin{array}{l}1 \\
0\end{array}$ & $\begin{array}{l}0 \\
0\end{array}$ & $\begin{array}{l}3 \\
2\end{array}$ & $\begin{array}{l}0 \\
0\end{array}$ \\
\hline Fibrosarcoma & 5 & & & 0 & 2 & 0 & 3 & 0 \\
\hline HAE $†$ & 1 & & & 0 & 1 & 0 & 0 & 0 \\
\hline Synovial cell sarcoma & 1 & Monophasic & & 0 & 0 & 0 & 1 & 0 \\
\hline All malignant tumours & 85 & & & 1 & 7 & 2 & 70 & 5 \\
\hline Giant cell tumour & 10 & & & & ent $\mathrm{A}$ & 1 & a & \\
\hline
\end{tabular}

* malignant fibrous histiocytoma

† haemangioendothelioma

the wound had healed, and patients were allowed up, nonweight-bearing on crutches for a total of 42 days. Rehabilitation continued for several months after discharge from hospital. Patients were reviewed at regular intervals for clinical examination and plain radiography.

Assessment of results. At the final assessment, all radiographs were reviewed and graded for femoral diaphyseal remodelling according to the Rizzoli system (Fig. 3; Capanna et al 1989). The diaphyseal interface and anchorage were graded by the International Symposium of Limb Salvage (ISOLS) system, as was the tibial metaphyseal remodelling, interface and anchorage (Table II). Functional assessment used Enneking's gradings for pain, range of motion, stability, deformity, power, function and emotional acceptance (Enneking 1987).

Local recurrence. Five patients had local recurrence at an average of 15 months (2 to 39); three had osteosarcoma, one malignant fibrous histiocytoma, and one central chondrosarcoma. All five resections had been intraarticular with wide margins. Two of the three osteosarcoma patients had had a poor response to preoperative chemotherapy with necrosis of $<90 \%$. The third had received only postoperative chemotherapy. Three of the five patients died from metastatic disease before local recurrence could be treated, one had an amputation and one was lost to follow-up.

Other complications. Of the 95 patients, 51 (54\%) had complications requiring further surgery. One had an early amputation after several attempts to revise a thrombosed vascular bypass. Three patients required plastic surgery for wound necrosis or dehiscence.

Eleven patients $(12 \%)$ had infections and nine of these required reoperation. Five patients had primary infections requiring reoperation, three within two months
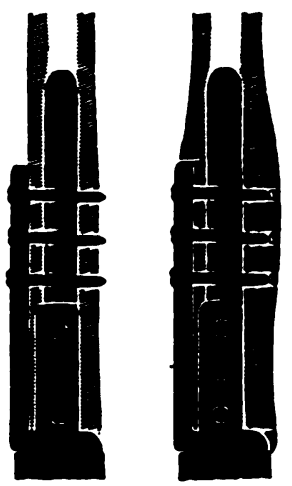

A

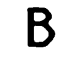

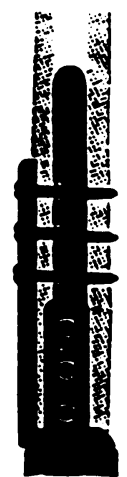

C

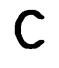

Fig. 3
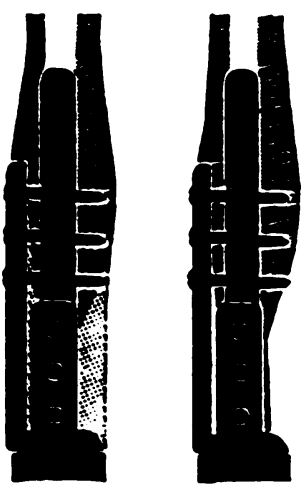

E
The Rizzoli grading system for diaphyseal remodelling around the KMFTR prosthesis. A, no change; B, cortical sclerosis; C, cortical cancellisation; D, biphasic response with distal sclerosis and proximal atrophy; $\mathrm{E}$, proximal lysis (see Figure 7).

of surgery and two at two and five years after resection, both after trauma with skin damage or bursitis. The other four infections were in revision procedures, three in previously infected cases and one in a non-infected case. Treatment was by wound debridement (1), arthrodesis with a vascularised fibular graft (1), revision procedures (3), and amputation (4). All nine patients were clear of infection at their latest follow-up. The patients who retained their prostheses after treatment for infection all had unsatisfactory results ( 3 poor, 1 fair), as did the patient with an arthrodesis (poor). Both patients treated without reoperation are on long-term antibiotics: one has a chronic low-grade prosthetic infection; the other has no evidence of infection at latest follow-up. 
Table II. International Symposium of Limb Salvage system for radiological assessment of prostheses

\begin{tabular}{|c|c|c|c|}
\hline Grade & Bone remodelling & Interface & Anchorage \\
\hline Excellent & No change & No RL line* & $\begin{array}{l}\text { a) No change } \\
\text { b) OK cement technique }\end{array}$ \\
\hline Good & $\begin{array}{l}\text { a) Hypertrophy } \\
\text { b) Sclerosis, or } \\
\text { c) Osteopaenia with no } \\
\text { geometrical change } \\
\text { d) Bone angulation }<5^{\circ}\end{array}$ & $\begin{array}{l}\mathrm{RL} \text { line }<2 \mathrm{~mm} \text { thick } \\
<1 / 3 \text { length }\end{array}$ & $\begin{array}{l}\text { Inadequate cementation } \\
\text { but no change or failure }\end{array}$ \\
\hline Fair & $\begin{array}{l}\text { a) Osteolysis or } \\
\text { hypotrophy of fixation } \\
\text { area }<50 \%+>1 / 3 \\
\text { length } \\
\text { b) Bone angulation }>5^{\circ}\end{array}$ & $\begin{array}{l}\mathrm{RL} \text { line }<2 \mathrm{~mm}+>1 / 3 \\
\text { length } \\
\text { Axial migration }<5 \mathrm{~mm}\end{array}$ & $\begin{array}{l}\text { a) Stem deformation } \\
\text { b) Screw fracturet } \\
\text { c) Plate fracture } † \\
\text { d) Cement fracture } \dagger\end{array}$ \\
\hline Poor & $\begin{array}{l}\text { a) Osteolysis or } \\
\text { hypotrophy of fixation } \\
\text { area }>50 \% \text { thick }+>1 / 3 \\
\text { length } \\
\text { b) Bone fracture }\end{array}$ & $\begin{array}{l}\text { a) } \mathrm{RL} \text { line }>2 \mathrm{~mm}+>1 / 3 \\
\text { length, or } \\
\text { b) }>5 \mathrm{~mm} \text { axial } \\
\text { migration, or } \\
\text { c) Loosening }\end{array}$ & $\begin{array}{l}\text { a) Stem fracture } \\
\text { b) Screw } \ddagger \\
\text { c) Plate } ¥ \\
\text { d) Cement } \ddagger\end{array}$ \\
\hline
\end{tabular}

* radiolucent line

$\dagger$ no loosening

$\ddagger$ fracture with loosening

The incidence of infection correlated directly with the extent of quadriceps excision, cases including two with vastus medialis and intermedius excisions, two after excision of all vasti, five with total quadriceps excision and two after excision of all vasti with biceps and hamstrings.

Late traumatic fractures of the femur above the stem of the prosthesis occurred in three cases. One was at the tip of the stem, and was treated with a vitallium plate and screws after removal of the long lateral plate of the prosthesis. Subsequently, there was a metallosis reaction to the titanium causing rapid cortical osteolysis which necessitated revision of both plate and prosthesis. The second patient had a subtrochanteric fracture of the femur above the prosthesis, treated successfully by a femoral plate. The third had a femoral neck fracture above a long resection, and lack of bone stock necessitated conversion to a total femoral replacement using the KMFTR system. One other patient had a tibial fracture which was treated conservatively.

Six patients had fracture of the femoral stem (Fig. 4), all treated by revision to a new KMFTR prosthesis. Five of the fractures occurred through the proximal screw hole, and the other was at the base of the stem (Table III). In all six cases the diaphyseal interface showed good or excellent integration. One other patient had a fracture of the tibial ring component which was treated by revision. These prosthetic breakages occurred in one case after partial vastus excision, three after complete vasti excision with retention of the rectus, one after complete quadriceps excision and two after conversion from an arthrodesis. In no case did the clinical grade of the result change after revision of the stem.

Failure of the polyethylene bushes needed reoperation in 28 patients $(30 \%)$ and another 11 are awaiting such surgery, giving a total incidence of $41 \%$. Failure of

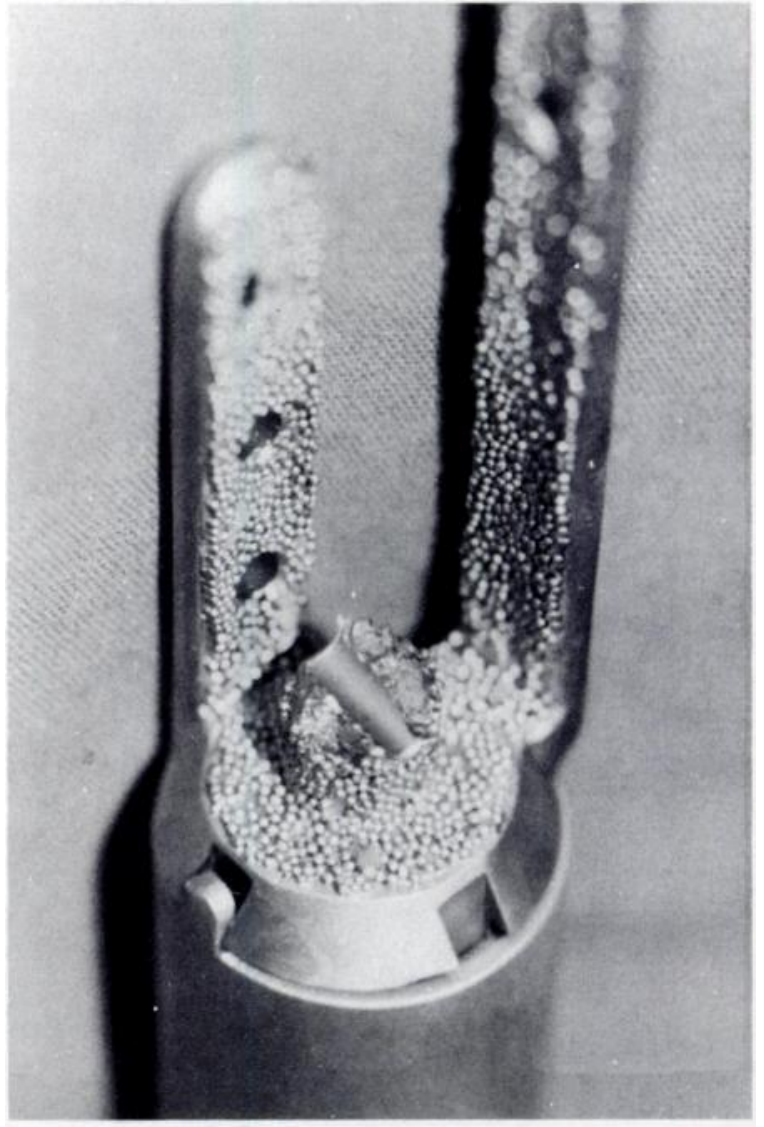

Fig. 4

A $10 \mathrm{~mm}$ diameter stem which broke 20 months after implantation. All but one of the six stem breakages were at the first screw hole.

the bushes causes varus-valgus instability, locking and clicking, but is usually painless (Fig. 5). The average time to failure of the bushes was 64 months (24 to 95). The clinical grade altered after bush replacement in only two 
Table III. Details of six cases of stem breakage

\begin{tabular}{llllll}
\hline $\begin{array}{l}\text { Stem diameter } \\
(\mathbf{m m})\end{array}$ & $\begin{array}{l}\text { Time } \\
(\mathbf{m t h})\end{array}$ & $\begin{array}{l}\text { Diaphyseal } \\
\text { remodelling }\end{array}$ & $\begin{array}{l}\text { Quadriceps } \\
\text { excision* }\end{array}$ & Treatment & $\begin{array}{l}\text { Clinical } \\
\text { result } \dagger\end{array}$ \\
\hline 10 & 50 & A & VI, VM & Revision & Poor \\
10 & 49 & B & VI, VM, VL & $\begin{array}{l}\text { Amputation } \\
\text { for infection }\end{array}$ & - \\
10 & 20 & B & VI, VM, VL & Revision & Good \\
10 & 55 & E & VI, VM, VL & Total femur & Good \\
13 & 59 & A & VI, VM, VL, RF & Revision & Good \\
13 & 26 & A & Ex arthrodesis & Revision & Good \\
\hline
\end{tabular}

* VI, vastus intermedius; VM, vastus medialis; VL, vastus lateralis; RF, rectus femoris $\dagger$ after revision

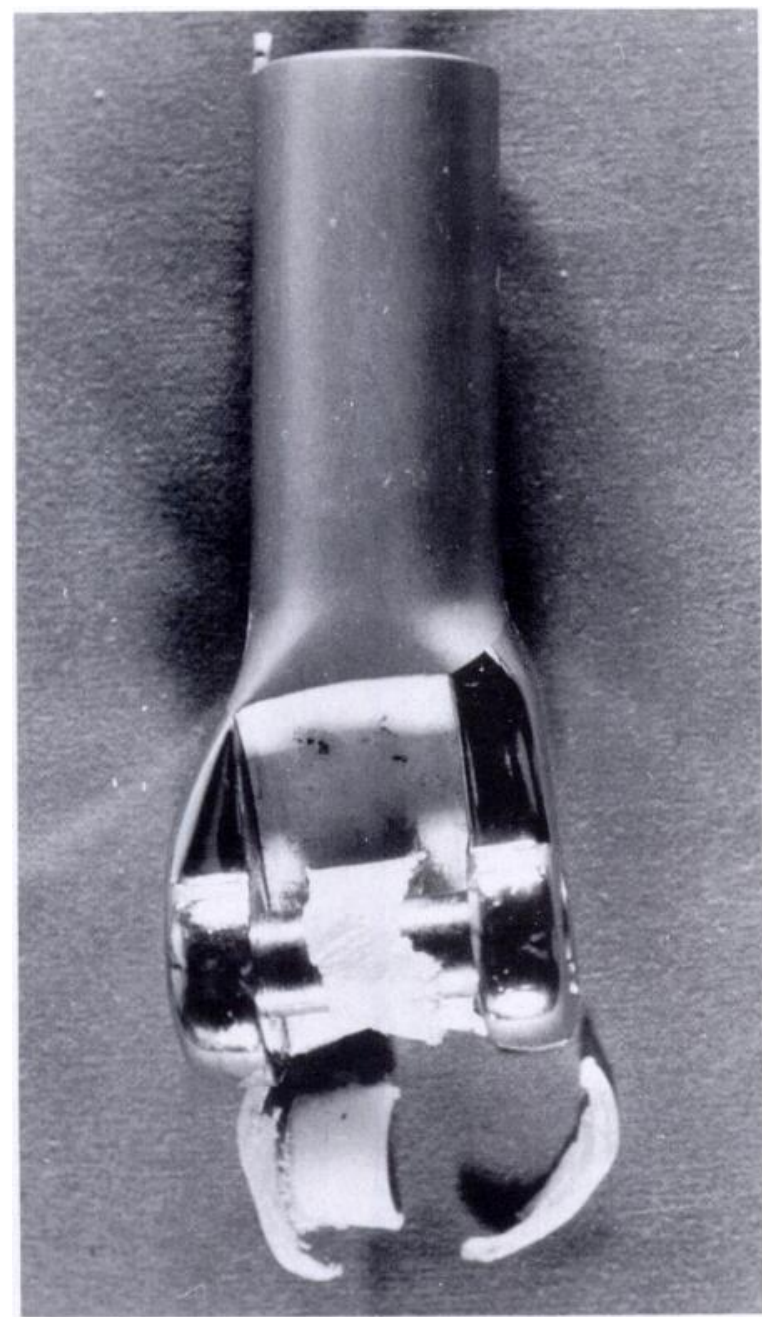

Fig. 5

Failure of the polyethylene bushes was the most common complication and reason for revision.

of the 28 patients: one deteriorated from a good to a fair result, and one improved from good to excellent.

In one patient, uncoupling of the femoral stem from the connecting piece was successfully dealt with by replacement to give a good result.

Other complications which did not require reopera- tion included haematoma requiring aspiration (7), common peroneal nerve palsy (3), pulmonary embolus (2), and one case of mild reflex sympathetic dystrophy which responded to physiotherapy. The one early postoperative death was due to pulmonary embolism. No revisions were required for radiological or clinical loosening.

\section{RESULTS}

Patients who died early from metastatic disease were usually lost to follow-up when their radiological evaluation was still excellent. Our review of radiological changes was limited therefore to those with three-year (62) and five-year (36) results. Clinical results were assessed at the latest follow-up.

Clinical results. Of the 95 patients, 84 were available for late clinical review. Twenty $(24 \%)$ had an excellent result, $43(51 \%)$ were good, $12(14 \%)$ were fair and $9(11 \%)$ were poor. Of the other 11 patients, six had had an amputation (four for infection, one for ischaemia and one for local recurrence). One patient had had an arthrodesis, two had died before evaluation, one had died and one had an early amputation.

The nine with poor results had poor scores in at least two of the seven parameters used in Enneking's system, and their details are given in Table IV. The clinical results were then correlated with the radiological results (Table V). We found no clear correlations between radiologically and clinically poor results.

The results are related to the amount of the quadriceps excised in Table VI. Patients with conversion from a K rod and cement arthrodesis to a hinged knee all had poor quadriceps function and are recorded separately.

\section{Radiological results}

Diaphyseal bone remodelling. Table VII shows the grade of diaphyseal remodelling in various follow-up groups.

There is a relative increase in grades $\mathrm{D}$ and $\mathrm{C}$ with longer follow-up and a decrease in grade $\mathrm{A}$ (unchanged). The incidence of grades $\mathrm{B}$ and $\mathrm{E}$ remains relatively constant.

We then correlated the results in the 62 cases assessed at three years with age, chemotherapy, length of 
Table IV. Details of nine patients with clinically poor results, in at least two Enneking categories

\begin{tabular}{lllll}
\hline Case & Previous surgery & Complication & Treatment & Features \\
\hline 1 & None & Stem fracture & Revision & Pain, fixed flexion deformity \\
2 & None & $\begin{array}{l}\text { Patellar } \\
\text { subluxation }\end{array}$ & Conservative & Pain, dislikes \\
3 & K rod arthrodesis & Infection & Revision & Pain, stiffness \\
4 & None & Infection & Revision & Pain, stiffness \\
5 & None & Infection & Revision & Stiffness, dislikes \\
6 & K rod arthrodesis & Bush failure & Awaiting & Instability, stiffness \\
7 & $\begin{array}{l}\text { Plate and cement } \\
\text { (infected) }\end{array}$ & Nil & Nil & ROM ${ }^{*}<15^{\circ}, 3 \mathrm{~cm}$ short \\
8 & $\begin{array}{l}\text { K rod arthrodesis } \\
\text { (infected) }\end{array}$ & Nil & Nil & ROM $<10^{\circ}$, instability \\
9 & None & Nil & Nil & ROM $<15^{\circ}, 2.5 \mathrm{~cm}$ short \\
\hline range of motion & & &
\end{tabular}

Table V. Correlation of clinical grade with radiological grade

\begin{tabular}{llrrrr}
\hline & & \multicolumn{3}{c}{ Clinical grade* } \\
\cline { 3 - 6 } & Grade & E & G & F & P \\
\hline Diaphyseal & & & & & \\
Remodelling (\%) & A & 33 & 38 & 34 & 33 \\
& B & 21 & 17 & 0 & 17 \\
& C & 13 & 3 & 0 & 34 \\
& D & 33 & 34 & 50 & 16 \\
& E & 0 & 8 & 16 & 0 \\
Interface (\%) & E & 86 & 80 & 83 & 83 \\
& G & 14 & 10 & 0 & 17 \\
& F & 0 & 0 & 17 & 0 \\
& P & 0 & 10 & 0 & 0 \\
Anchorage (\%) & E & 87 & 84 & 100 & 100 \\
& G & 0 & 0 & 0 & 0 \\
& F & 13 & 6 & 0 & 0 \\
& P & 0 & 10 & 0 & 0 \\
Metaphyseal & & & & & \\
Remodelling (\%) & E & 60 & 55 & 33 & 0 \\
& G & 40 & 45 & 67 & 100 \\
& F & 0 & 0 & 0 & 0 \\
& P & 0 & 0 & 0 & 0 \\
Interface (\%) & E & 60 & 63 & 50 & 50 \\
& G & 30 & 31 & 50 & 33 \\
& F & 10 & 3 & 0 & 0 \\
& P & 0 & 3 & 0 & 17 \\
Anchorage (\%) & E & 100 & 70 & 100 & 85 \\
& G & 0 & 30 & 0 & 15 \\
& F & 0 & 0 & 0 & 0 \\
& P & 0 & 0 & 0 & 0 \\
\hline Exyyyyy & & & & & \\
& & & & &
\end{tabular}

* excellent, good, fair, poor

resection, number of cross screws and stem diameter. There were no clear correlations with the age of the patient, the use of intravenous or intra-arterial chemotherapy, the length of femoral resection or the diameter of the stem. There was, however, a correlation between screw fixation and the remodelling grade. Prostheses with complete fixation by three screws through each plate had more type $\mathrm{C}, \mathrm{D}$ and $\mathrm{E}$ responses at 36 months than did
Table VI. Correlation of quadriceps excision and clinical grade in 84 patients available for final clinical follow-up

\begin{tabular}{lccccc}
\hline & & \multicolumn{4}{c}{ Clinical grade by number (percentage) } \\
\cline { 3 - 6 } Quadriceps excision* & Number & Excellent & Good & Fair & Poor \\
\hline VI & 7 & $4(57)$ & $2(28)$ & 0 & $1(14)$ \\
VI+VM & 17 & $6(35)$ & $7(41)$ & $1(6)$ & $3(18)$ \\
VI+VL & 19 & $6(32)$ & $11(58)$ & $1(5)$ & $1(5)$ \\
VI+VM+VL & 20 & $4(20)$ & $12(60)$ & $3(15)$ & $1(5)$ \\
VI+VL+VM+RF & 8 & 0 & $4(50)$ & $4(50)$ & 0 \\
Conversion arthrodesis $\dagger$ & 13 & 0 & $7(54)$ & $3(23)$ & $3(23)$ \\
\hline
\end{tabular}

* VI, vastus intermedius; VM, vastus medialis; VL, vastus lateralis; $R F$, rectus femoris

† these patients were converted from an arthrodesis to hinged knee

Table VII. Diaphyseal remodelling related to length of follow-up (percentage)

\begin{tabular}{lllllll}
\hline & \multicolumn{3}{c}{ Grade* } \\
\cline { 2 - 7 } & A & B & C & D & E \\
\hline All available $(\mathrm{n}=93)$ & 46 & 17 & 4 & 25 & 8 \\
Three years $(\mathrm{n}=62)$ & 34 & 18 & 6 & 35 & 6 \\
Five years $(\mathrm{n}=36)$ & 19 & 19 & 8 & 42 & 11 \\
\hline * see figures & & & & &
\end{tabular}

those with incomplete fixation by three screws passed only through the short plate (Fig. 6). In six cases, cortical erosions appeared beneath the unused long lateral plate. Diaphyseal interface between stem and bone. This interface was assessed by the ISOLS grade. At 36-month follow-up of 62 cases the grades were excellent in $79 \%$, good in $13 \%$, fair in $2 \%$ and poor in $6 \%$. The four poor cases were all associated with poor anchorage due to screw breakages, but had A or B grades for remodelling. At the 60 -month follow-up of 36 cases, the grades were 


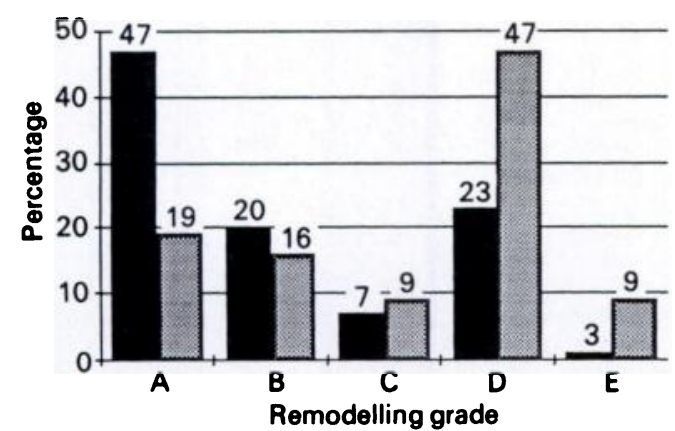

Fig. 6

Relation between the number of screws used for fixation and the grade of diaphyseal remodelling (A to E, see Figures 3 and 7).

excellent in $62 \%$, good in $22 \%$, fair in $3 \%$ and poor in $13 \%$.

We did not find any clear correlations with age, chemotherapy, length of resection, screw fixation or stem diameter. All but one of the fair and poor interface results were associated with good clinical results.

Diaphyseal anchorage. The anchorage was also graded according to the ISOLS system. We did not use cement, and stem breakage has been recorded under complications. We were therefore assessing only screw behaviour. At 36 months in 62 cases the anchorages were excellent in $88 \%$, fair in $6 \%$, and poor in $6 \%$. At 60 months the results were excellent (78\%), fair (11\%), and poor (11\%). Again, we found no correlation with age, chemotherapy, length of resection, screw fixation or stem diameter. The eight failures ( 4 fair and 4 poor) were so graded because of the breakage of one or more screws. The poor results showed loosening and migration; the fair results had screw fracture but no loosening. All these failures had grade A or B diaphyseal remodelling at follow-up, and the clinical results were excellent in two and good in six.

Metaphyseal tibial assessment. Using the ISOLS system the results at 36 months were excellent in $47 \%$, good in $50 \%$, fair in $3 \%$ and poor in none. Remodelling was excellent in $57 \%$, good in $35 \%$, fair in $5 \%$ and poor in $3 \%$. For the interface and for anchorage the results were excellent in $97 \%$ and good in 3\%. There was no increase in unsatisfactory results at 60 months.

\section{DISCUSSION}

We used the original KMFTR system from 1983 until certain modifications were made to the prosthesis in 1989. By then we had performed 95 distal femoral resections and reconstructions with the system.

We recorded a high incidence of complications $(55 \%)$. Of the 11 infections, nine required reoperation. For primary cases the infection rate was an acceptable 5\% (3\% early and $2 \%$ late). Four infections were in revision cases, three of which had prior infection, giving an infection rate for previously infected cases of $43 \%$, and for those without prior infection of $6 \%$. Five infections had successful limb salvage, but had fair (1) or poor (4) clinical assessments.

Infection of large prostheses is a catastrophic complication, and even technically successful salvage gives poor function; sometimes amputation may be thought to give a more satisfactory result. Many patients, however, would prefer to retain a poorly functioning limb rather than undergo an amputation. In our series of 95 patients only four underwent amputation for infection.

We found a higher risk of infection when most or all of the vasti and rectus had been excised; good local muscle coverage of the prosthesis is obviously important. Consideration should be given to providing local or freeflap coverage if much of the quadriceps has to be excised (Klein, Kenan and Lewis 1989).

The polyethylene bushes of the hinge provided a major problem, needing 28 revisions with another 11 awaiting surgery. The average time to failure was 64 months and even the relatively minor revision required adds risks, particularly of infection. The simple hinge joint does not allow for varus, valgus and rotary forces, and these lead to excessive wear and failure of the bushes. Either wear resistance must be increased or the forces decreased. The introduction of a rotating hinge (Walker et al 1982) may reduce the rotary forces, and other changes in configuration may help, and are being studied.

We recorded six femoral stem fractures $(6 \%)$ at an average of 43 months. Five were through the proximal screw hole, close to the base of the prosthesis (see Fig. 4 ), and therefore unprotected by host bone. The fractures were in four $10 \mathrm{~mm}$ and two $13 \mathrm{~mm}$ stems with none in $16 \mathrm{~mm}$ stems; this suggests that the smaller stems are more subject to fatigue stress. Most stem breakage was associated with the larger excisions of quadriceps. After total quadriceps excision, a passive extension gait means that the block stabilising extension is provided by the prosthesis with no help from quadriceps contraction, as observed by Van Krieken et al (1985) and the stem is subjected to higher stress. After total or near-total quadriceps excision, consideration should be given to using the largest possible stem to reduce the chance of stem fracture.

According to the Enneking system for functional evaluation we had $75 \%$ excellent or good results at latest follow-up. Six of our nine poor results were the results of complications, particularly infection. Of the other three patients with poor results, two had prior arthrodesis with infection; only one had neither preceding infection nor postoperative complications. We found no correlation between the radiological and the functional results: an excellent functional result may be associated with a poor radiological result and vice versa.

Quadriceps excision ranged from vastus intermedius only to complete removal of the muscle, including the rectus femoris. Our results confirm the previous suggestion (Capanna et al 1991) that complete excision may result in a reasonably successful outcome with time allowing 


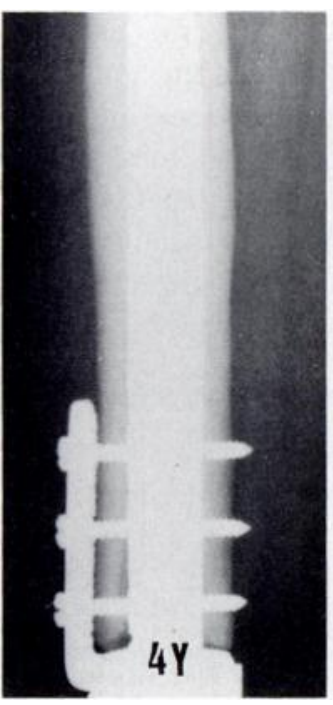

Fig. 7A

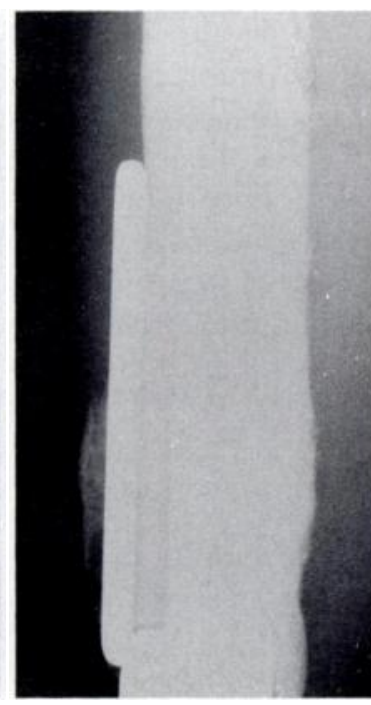

Fig. 7B

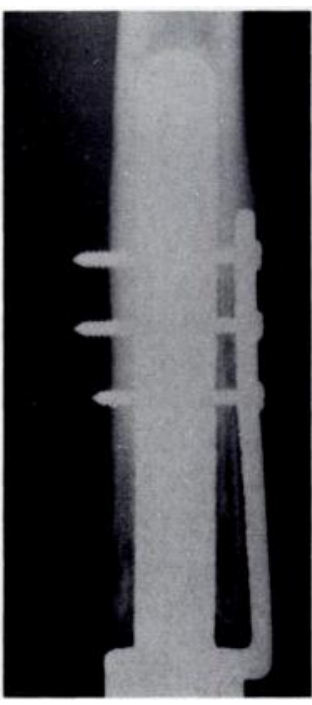

Fig. 7C

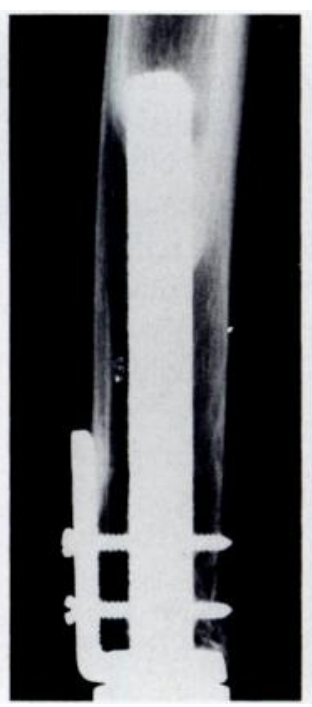

Fig. 7D

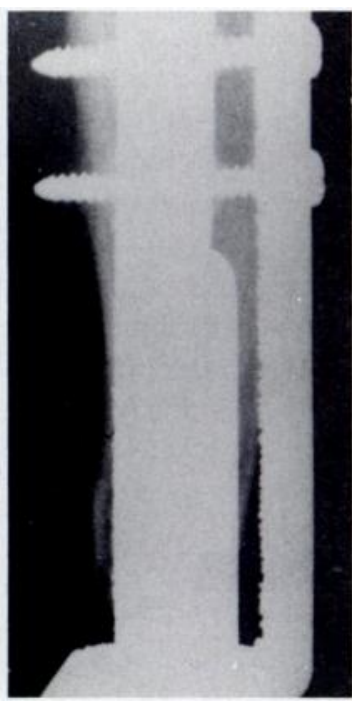

Fig. 7E

Radiological cortical remodelling around the stem: A, no change; B, cortical sclerosis; C, cortical cancellisation; D, biphasic response, with distal sclerosis and proximal osteoporosis; E, proximal lysis.

patients adequate walking with a passive extension gait. There was a tendency to worse clinical results when more of the quadriceps was excised, but even the most radical resection could in time result in good function.

In hip replacement, bone remodelling and cortical atrophy due to stress shielding are recognised problems (Bobyn et al 1992; Huiskes, Weinans and van Rietbergen 1992; Sumner and Galante 1992), especially where there is rigid distal fixation. Similar concerns may apply to the diaphyseal segment after distal femoral reconstructions. We describe five types of remodelling of the diaphyseal segment. Radiological types A (no change) and B (sclerosis) represent a stable situation that implies a favourable long-term prognosis. These grades correspond to the excellent and good grades in the ISOLS classification system, but do not include consideration of bone angulation or osteopaenia. We found that grade A and B responses were more often seen in stems fixed with three rather than with six screws. The radiological types $\mathrm{C}$ (cancellisation), D (biphasic) and E (proximal atrophy or osteolysis) are less satisfactory (fair and poor on the ISOLS system) and imply stress shielding (Fig. 7). We found these changes often in stems that had been stabilised with six screws, three in each plate. We therefore now use fixation with only three screws. This provides enough early stability for bone ingrowth and fixation but reduces stress shielding caused by proximal screws. It is not yet clear whether primary fixation with screws is necessary; it may be that the complete absence of screws will further reduce stress shielding.

On the ISOLS grading, the diaphyseal interface was excellent or good in $84 \%$ at 60 months. Many of our cases showed a fine sclerotic line surrounding, but separate from the prosthesis. The presence of intervening trabecular bone suggested that there had been good ingrowth of bone on to the prosthesis. The interfaces graded poor, showing a radiolucent line greater than $2 \mathrm{~mm}$ for more than one-third of the length of the prosthesis, or migration or loosening, were not associated with a poor clinical result. They were, however, associated with screw fractures, which suggests that failure of initial stabilisation and bone ingrowth may lead to screw fracture. We do not believe that these cases need revision in the absence of clinical symptoms and in many cases progressive thickening of the cortex suggests that they may eventually be self-stabilising. These long-term radiological results for the diaphyseal segment are promising and compare favourably with other reported series (Sim and Chao 1979; Ritschl et al 1987; Eckardt et al 1987; Malawer 1992).

We have seen few problems with the tibial metaphysis: bone ingrowth of the proximal tibia has been satisfactory, and the configuration lends itself to excellent anchorage. The many cases recorded as good rather than excellent in regard to remodelling were so graded because of some proximal osteoporosis. To reduce surgical exposure and operating time, and to decrease proximal osteoporosis, we have not used the tibial cross bolt recommended by Kotz et al (1986); this may have reduced the potential for proximal stress shielding.

There are many reports of the failure of noncemented tibial components in total knee arthroplasty, but we did not have this problem. A possible explanation for this is the relative youth of our patients, and the hinged configuration may account for some of the differences in response. The tibial prosthesis is designed for early stability and, coupled with our very conservative regime of postoperative rehabilitation, seems to favour an excellent long-term result.

Conclusions. The KMFTR is modular and easy to assemble. Quadriceps excision affects the overall functional rating and probably the incidence of infection and 
stem breakage. Long-term radiological changes are usually satisfactory and screw breakage is not an indication for revision since stabilisation may occur with time. Most clinical results are excellent or good, with no apparent correlation with radiological changes. There were numerous complications reflecting the difficult surgery and the often compromised health of the patients. The main problems were wear of the polyethylene bushes and stem fractures, usually through the proximal screw hole and in the smaller stems.

The KMFTR is a satisfactory prosthesis for recon-

\section{REFERENCES}

Bobyn JD, Mortimer ES, Glassman AH, et al. Producing and avoiding stress shielding: laboratory and clinical observations of non-cemented total hip arthroplasty. Clin Orthop 1992; 274:79-96.

Capanna R, Leonessa C, Bettelli G, et al. Modular Kotz prosthesis: the Rizzoli Experience. In: Yamamuro T, ed. New developments for limb salvage in musculoskeletal tumours. Tokyo, etc: Springer-Verlag, 1989:37-44.

Capanna R, Ruggieri P, Biagini R, et al. The effect of quadriceps excision on functional results after distal femoral resection and prosthetic replacement of bone tumors. Clin Orthop 1991; 267:186-96.

Eckardt JJ, Eilber FR, Kabo JM, Mirra JM. Kinematic rotating hinge knee-distal femoral replacement. In: Enneking WF, ed. Limb salvage in musculoskeletal oncology. New York: Churchill Livingstone, 1987:392-409.

Enneking WF. Modification of the system for functional evaluation of surgical management of musculoskeletal tumors. In: Enneking WF, ed. Limb salvage in musculoskeletal oncology. New York: Churchill Livingstone, 1987:626-39.

Huiskes R, Weinans $\mathbf{H}$, van Rietbergen B. The relationship between stress shielding and bone resorption around total hip stems and the effects of flexible materials. Clin Orthop 1992; 274:124-34. struction of the distal femur after resections for sarcoma. To address the problems of stress shielding and stem fracture we introduced several modifications in 1989, including the use of only one flange for fixation by only three screws, a smooth tip to the stem, an anatomically shaped stem with screw holes placed more distally, and a greater choice of stem diameters. We are currently assessing modifications to the hinge mechanism.

This research was supported by Consiglio Nazionale Ricerche Funds.

No benefits in any form have been received or will be received from a commercial party related directly or indirectly to the subject of this article.

Klein MJ, Kenan S, Lewis MM. Osteosarcoma: clinical and pathological considerations. Orthop Clin North Am 1989; 20:3:327-45.

Kotz R, Ritschl P, Trachtenbrodt J. A modular femur-tibia reconstruction system. Orthopaedics 1986; 9:1639-52.

Malawer MM. Distal femoral resection for sarcomas of bone. In: Sugarbaker PH, Malawer MM. Musculoskeletal surgery for cancer: principles and techniques. Thiem, New York: 1992; 243-59.

Ritschl P, Braun O, Pongracz N, et al. Modular reconstruction system for the lower extremity. In: Enneking WF, ed. Limb salvage in musculoskeletal oncology. New York, etc: Churchill Livingstone, 1987:237-43.

Sim FH, Chao EYS. Prosthetic replacement of the knee and large segment of the femur or tibia. J Bone Joint Surg [Am] 1979; 61-A:887-92.

Sumner DR, Galante JO. Determinants of stress shielding: design versus materials versus interface. Clin Orthop 1992; 274:202-12.

Van Krieken FM, den Heeten GJ, Pedersen DR, Brand RA, Crowninshield RD. Prediction of muscle and joint loads after segmental femur replacement for osteosarcoma. Clin Orthop 1985; 198:273-83.

Walker PS, Emerson R, Potter T, et al. The kinematic rotating hinge: biomechanics and clinical application. Orthop Clin North Am 1982; 13:187-99. 